\title{
Potentiation of diaphragmatic twitch after voluntary contraction in normal subjects
}

\author{
S Wragg, C Hamnegard, J Road, D Kyroussis, J Moran, M Green, J Moxham
}

\begin{abstract}
Background - Skeletal muscle twitch responses may be transiently increased by previous contractions, a phenomenon termed twitch potentiation. The aim of this study was to examine the extent and time course of diaphragmatic twitch potentiation and its relationship to both the magnitude and duration of the preceding voluntary diaphragmatic contraction. Methods - Twitch transdiaphragmatic pressure (PDI) was measured in six normal subjects, before and after voluntary diaphragm contractions of $100 \%, 75 \%, 50 \%$, and $25 \%$ of maximum PDI (PDImax) sustained for five and 10 seconds.

Results - Twitch PDI was significantly increased after $100 \%, 75 \%$, and $50 \%$ contractions. Following maximal contractions sustained for 10 seconds the mean increase in twitch PDI was 52\%. Following 50\% contractions sustained for five seconds the mean increase in twitch height was $28 \%$. In all runs twitch PDI returned to rested levels within 20 minutes.

Conclusions - Twitch potentiation can be substantial, even following submaximal contractions, and must be taken into account when twitch pressure is used to assess diaphragm contractility.
\end{abstract}

(Thorax 1994:49:1234-1237)

Department of Thoracic Medicine, King's College Hospital, London SE5 9PJ, UK S Wragg

C Hamnegard

D Kyroussis

J Moxham

Respiratory Muscle Laboratory,

The Royal Brompton

Hospital, London

SW3 6NP, UK

J Road

M Green

Department of Intensive Care, Queen Elizabeth Hospital,

Adelaide, South

Australia 5011

J Moran

Reprint requests to: Dr S Wragg.

Received 9 March 1994

Returned to authors

27 April 1994

Revised version received

13 September 1994

Accepted for publication

19 September 1994
Diaphragm contractility is conventionally assessed by the measurement of transdiaphragmatic pressure. When assessing diaphragm strength, normal subjects or patients are required to make maximum voluntary inspiratory efforts. Commonly used manoeuvres include a quasi static inspiratory effort against a closed airway ${ }^{1}$ and a maximal sniff. ${ }^{2}$ Voluntary manoeuvres are useful when assessing diaphragm weakness ${ }^{3}$ but patients are sometimes unable to make maximum efforts. Electrical stimulation of the phrenic nerves percutaneously in the neck ${ }^{4}$ and the measurement of twitch diaphragmatic pressure (PDI) has the advantage of providing a non-volitional index of diaphragm strength. The twitch technique has been used to study diaphragm fatigue, ${ }^{56}$ weakness, ${ }^{7}$ the influence of drugs, ${ }^{89}$ and the effect of lung volume on diaphragm contractility. ${ }^{1011}$ Electrical stimulation can be uncomfortable for patients and technically difficult; the recent introduction of magnetic phrenic nerve stimulation may overcome these difficulties. ${ }^{12}$ The usefulness of twitch PDI is influenced by the stability of the contractile response. In limb muscle the twitch response is affected by prior voluntary efforts, a phenomenon referred to as twitch potentiation. ${ }^{13}$ Substantial twitch potentiation of the diaphragm could be of importance for both physiological studies and clinical evaluation; twitch PDI is commonly recorded soon after maximal and near maximal voluntary diaphragm contractions.

The aim of this study was to examine the extent and time course of diaphragmatic twitch potentiation and its relationship to both the magnitude and duration of the preceding voluntary diaphragmatic contraction.

\section{Methods}

Oesophageal and gastric pressures were recorded from latex balloon catheters (PK Morgan 71510) positioned and tested in the standard manner. ${ }^{1415}$ Pressures were measured by Validyne MP45-1 differential pressure transducers (range $\pm 150 \mathrm{~cm} \mathrm{H}_{2} \mathrm{O}$, Validyne $\mathrm{Co}$, Northridge, California, USA). PDI was obtained by electrical subtraction of oesophageal from gastric pressure using PDI at resting end expiration as the reference point. ${ }^{16}$ All pressure signals were digitised via a 12 bit NB-MIO-16 (National Instruments, Austin, Texas, USA) analogue to digital converter and acquired into a Macintosh Centris 650 (Apple Computer Inc, Cupertino, California, USA) running LabVIEW software (National Instruments, Austin, Texas, USA), sampling at $100 \mathrm{~Hz}$ from each channel. We stimulated the phrenic nerve roots with a Magstim 200 (Magstim Co Ltd, Whitland, Dyfed, UK) and a circular $90 \mathrm{~mm}$ coil (P/N 9784-00). ${ }^{12}$ This technique stimulates nervous tissue by induced electric currents from a time varying magnetic field of brief duration. ${ }^{17}$ To stimulate the phrenic nerve roots the neck was flexed and the coil was placed over the spinous process of $\mathrm{C} 7$, moving up or down the midline between $\mathrm{C} 5$ and $\mathrm{C} 7$ until the maximum response was obtained ${ }^{18}$; thereafter all stimulations were performed at the same position. The phrenic nerves were stimulated with the subjects seated, wearing a nose clip and with the mouth closed. Magnetic stimulation was used in preference to electrical stimulation because of the ease with which the phrenic nerves can be stimulated and the high degree of reproducibility of the twitch PDI response. ${ }^{18}$ Chest wall and abdominal configuration were monitored with a respiratory inductive plethysmograph (Respitrace; Ambulatory Monitoring, Ardsley, New York, USA). All stimulations were performed at FRC at $100 \%$ Magstim output. 
Mean increases in twitch diaphragmatic pressure (PDI) 30 seconds after voluntary contractions

\begin{tabular}{|c|c|c|c|c|}
\hline \multirow[b]{2}{*}{$\begin{array}{l}\text { Magnitude of } \\
\text { voluntary } \\
\text { contraction }\end{array}$} & \multicolumn{2}{|c|}{10 second contractions } & \multicolumn{2}{|c|}{5 second contractions } \\
\hline & $\begin{array}{l}\text { Mean \% } \\
\text { increase of } \\
\text { twitch PDI }\end{array}$ & $95 \% C I$ & $\begin{array}{l}\text { Mean \% } \\
\text { increase of } \\
\text { twitch PDI }\end{array}$ & $95 \% C I$ \\
\hline $\begin{array}{r}100 \% \\
75 \% \\
50 \% \\
25 \%\end{array}$ & $\begin{array}{l}52^{* *} \\
40^{* *} \\
27^{*} \\
11\end{array}$ & $\begin{array}{r}32 \text { to } 72 \\
22 \text { to } 58 \\
6 \text { to } 49 \\
-6 \text { to } 28\end{array}$ & $\begin{array}{c}47^{* *} \\
41^{* *} \\
28^{* *} \\
5.4\end{array}$ & $\begin{array}{r}35 \text { to } 59 \\
23 \text { to } 60 \\
13 \text { to } 43 \\
-7 \text { to } 17\end{array}$ \\
\hline
\end{tabular}

${ }^{*} \mathrm{p}<0.05 ;{ }^{* *} \mathrm{p}<0.01$.
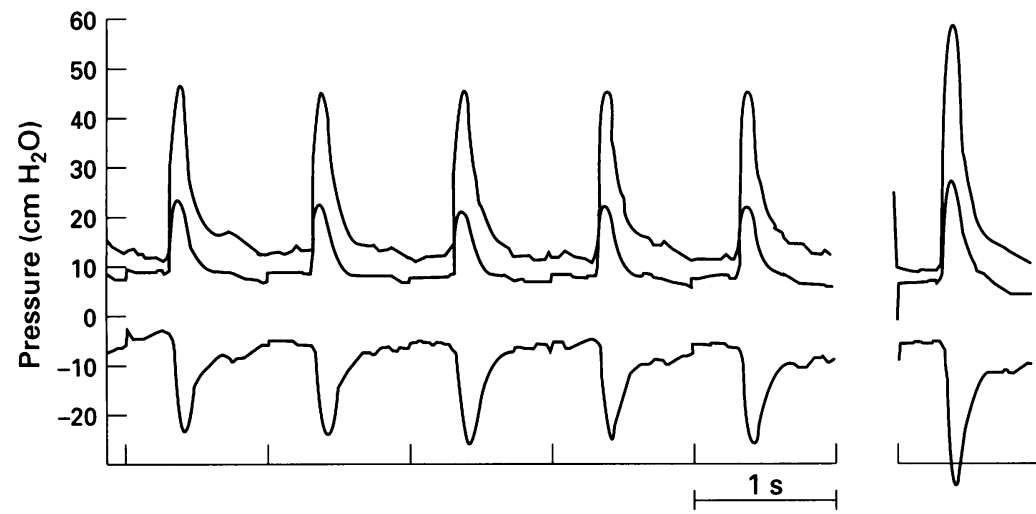

Figure 1 Five baseline twitches in a rested subject followed by a single twitch 30 seconds after a five second PDImax. Oesophageal pressure (POES) is displayed on the bottom trace, gastric pressure (PGA) on the middle, and diaphragmatic pressure (PDI) on the top.

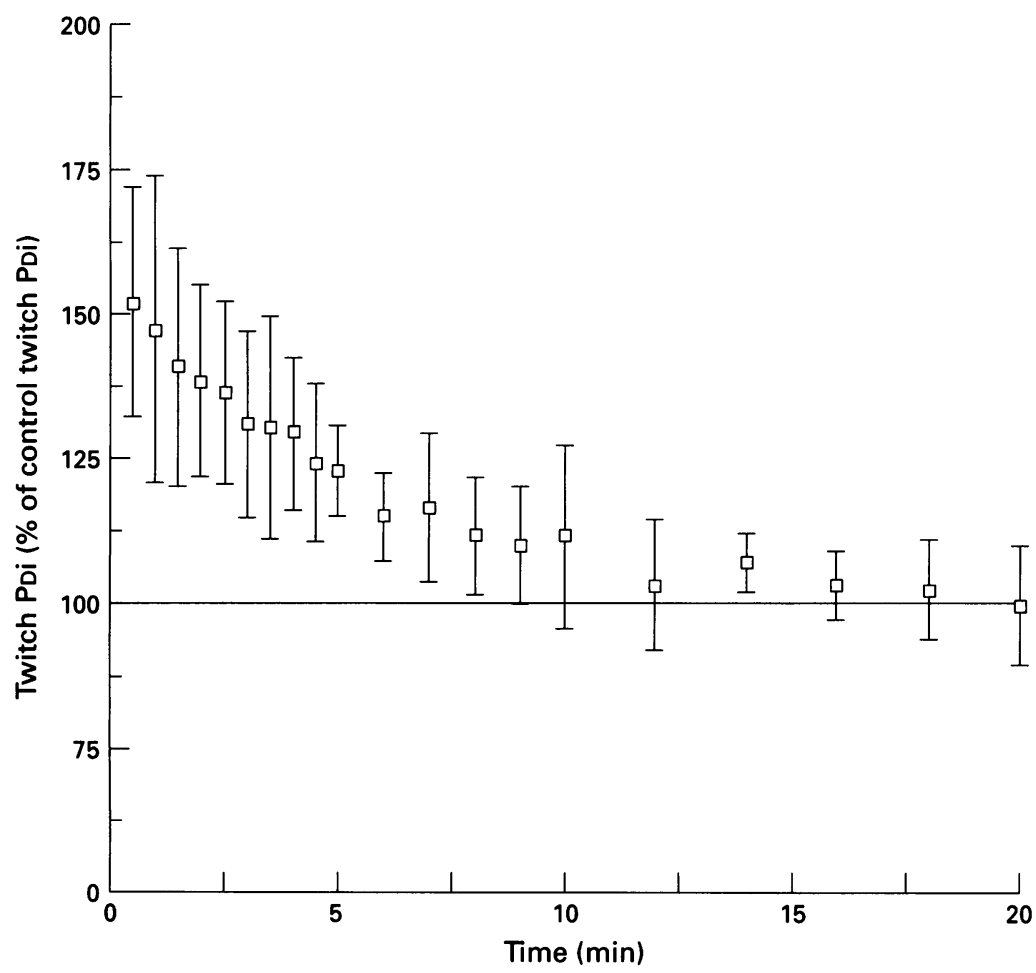

Figure 2 Mean and 95\% confidence interval of increase in twitch PDI following 10 second maximal voluntary contractions in six subjects.

Six normal men aged 31-45 years were studied. Subjects gave informed consent and the protocol was approved by the hospital ethics committee. In order to determine PDImax, PDI was displayed on an oscilloscope for the subject to view. The subject was then encouraged to perform a maximal inspiratory manoeuvre from FRC against a closed airway. On subsequent occasions subjects generated $100 \%, 75 \%, 50 \%$, or $25 \%$ of their PDImax for either five or 10 seconds. Each subject performed each of the eight sustained inspiratory efforts. Five second runs and 10 second runs were performed on separate days. The four graduated efforts were performed in random order with one hour separating inspiratory efforts. On each occasion subjects rested for 30 minutes and then received five twitches to establish baseline twitch PDI. Following the voluntary contractions subjects received 20 twitches during the subsequent 20 minutes commencing 30 seconds after the contractions.

In two further studies the phrenic nerves were stimulated percutaneously at the posterior border of the sternomastoid muscle at the level of the cricoid cartilage by two pairs of bipolar surface stimulating electrodes (Medelec 53054) with felt tips $5 \mathrm{~mm}$ in diameter. The electrodes were attached to a dual output isolated stimulator (Digitimer 3072). The stimulator produced square wave impulses of $0.1 \mathrm{~ms}$ in duration. The diaphragm EMG signals were displayed on a Tektronix 5013N storage oscilloscope. The voltage of stimulation was raised until there was no further increase in the size of the diaphragm muscle action potential. The voltage used was increased by a further $20 \%$ to ensure supramaximal stimulation. In the first of these studies twitch PDI was measured in two subjects before and 30 seconds after each of three five second PDImax manoeuvres one hour apart. In the second electrical study we recorded 10 twitch PDI responses from one subject and then the subject performed a five second PDImax manoeuvre. During the following 30 minutes 20 twitch PDI responses were recorded.

\section{Results}

The mean rested baseline twitch PDI was $29.5 \mathrm{~cm} \mathrm{H}_{2} \mathrm{O}$ (range 19.4-38.4). The mean within occasion coefficient of variation of the baseline twitch PDI was 5\% (range 4.2-6\%). The mean PDImax was $140.5 \mathrm{~cm} \mathrm{H}_{2} \mathrm{O}$ (range 110-157). The mean ratio of twitch PDI to PDImax was $0 \cdot 205$ (range $0 \cdot 175-0 \cdot 25$ ). Twitch PDI increased following maximal and submaximal voluntary contractions.

Figure 1 illustrates rested baseline twitches and subsequent twitch response 30 seconds after a five second PDImax in one subject. Results for twitch PDI 30 seconds after voluntary contractions are shown in the table. Following maximal, $75 \%$, and $50 \%$ contractions twitch PDI was significantly increased. Whilst the increase in twitch PDI failed to achieve significance for the group following $25 \%$ contractions, analysis of individual data revealed that twitch PDI was significantly raised $(p<0.05)$ in four of the six subjects following five second $25 \%$ contractions and in three subjects following 10 second $25 \%$ contractions.

Figure 2 shows the mean increase in twitch height following 10 second maximal contractions. Twitch height was significantly raised until 14 minutes. Results for the group are illustrated in fig 3. For all runs twitch PDI returned to control levels in 20 minutes.

In the two subjects stimulated electrically the mean increases in twitch PDI following five second PDImax manoeuvres were $40 \%$ and 

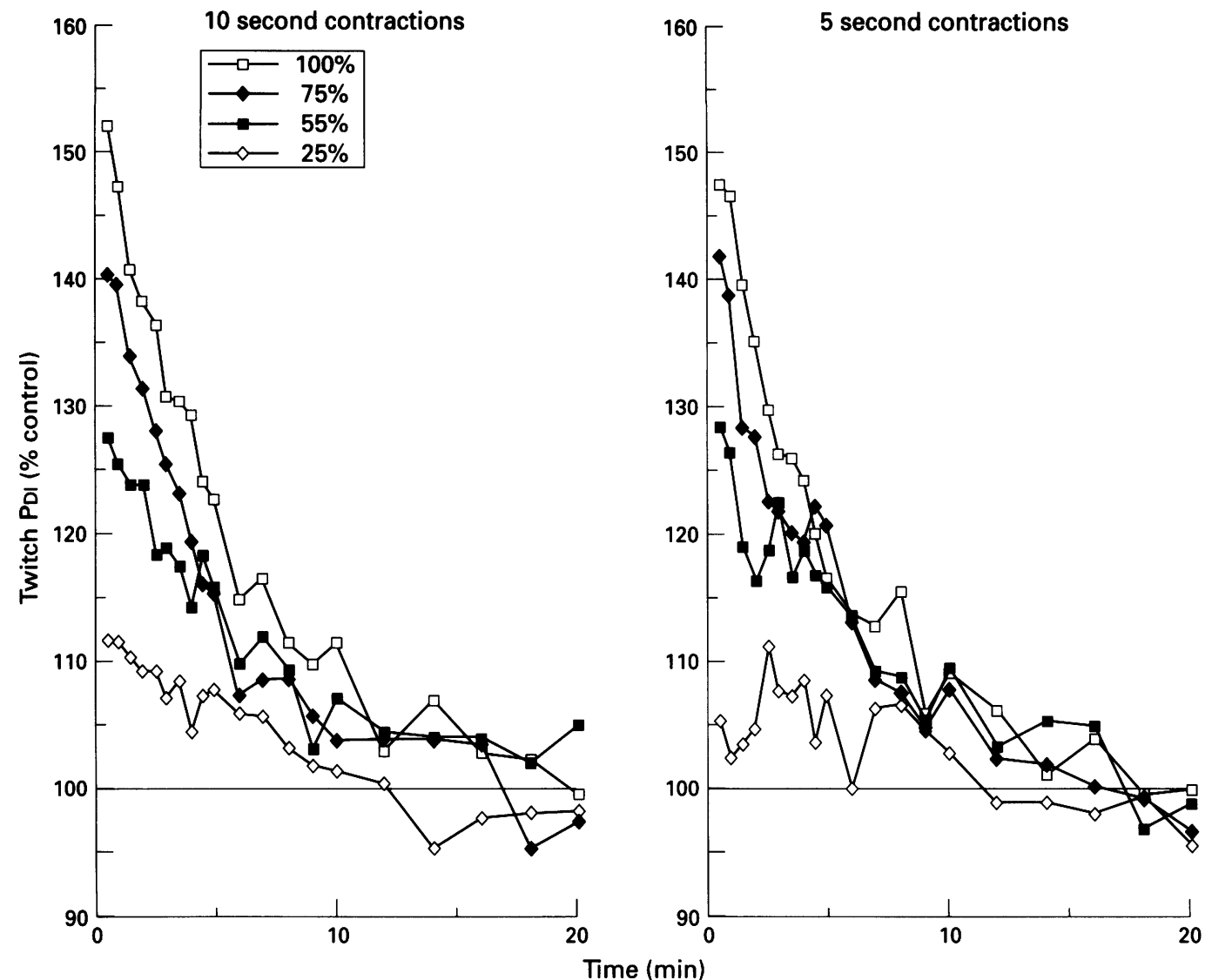

Figure 3 Mean increases in twitch PDI over time following voluntary contractions.

26\%. Figure 4 shows the return of twitch PDI to control values following a PDImax manoeuvre in one subject stimulated electrically.

\section{Discussion}

This study illustrates the magnitude of twitch potentiation following a maximal diaphragmatic contraction; the mean increase in twitch PDI was 52\%. Perhaps more importantly we have shown that submaximal diaphragmatic

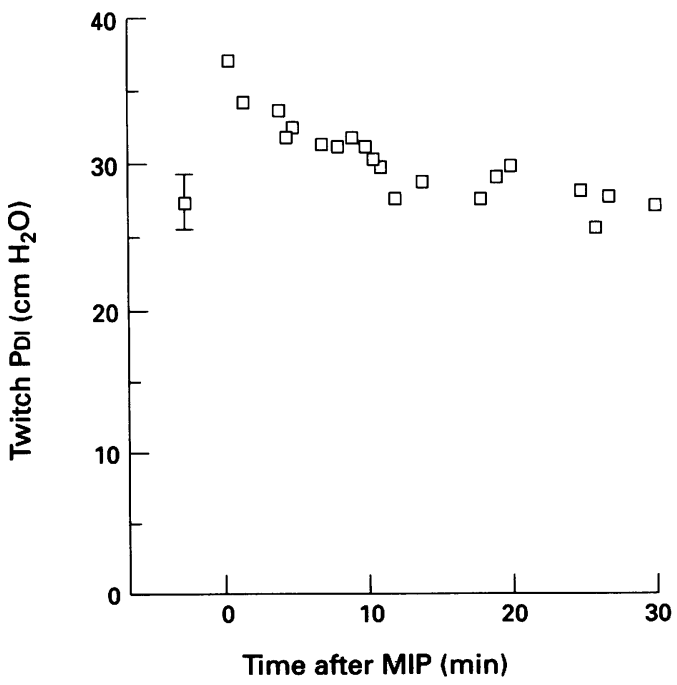

Figure 4 Twitch PDI obtained from supramaximal bilateral electrical phrenic stimulation in one subject following five second PDImax. Mean(SD) of control twitch PDI illustrated on left. contraction is also associated with a considerable increase in twitch PDI. Our results suggest that for sustained diaphragmatic contractions the intensity is the major determinant of the degree of potentiation rather than duration. Twitch PDI returned to rested values within 20 minutes following voluntary diaphragmatic contractions in all subjects.

Could the potentiation be an artefact of the form of phrenic nerve stimulation? We do not believe this is the case for the following reasons. (1) In the two subjects stimulated electrically the mean increases in twitch PDI following the PDImax were $40 \%$ and $26 \%$. Using magnetic stimulation in the same subjects twitch PDI increased by $41 \%$ and $30 \%$ respectively. (2) In one subject stimulated electrically the decay of twitch potentiation following a PDImax had a similar time course (fig 4) to that seen in the magnetic studies. (3) Mador et al, using electrical phrenic nerve stimulation, observed a 63\% (range 29-119\%) increase in twitch PDI following voluntary maximal diaphragmatic contractions. ${ }^{19}$ They also observed a $19 \%$ increase following submaximal contractions (33\% PDImax). In their study they reported no significant difference in the degree of potentiation observed after a single maximal one second voluntary contraction compared with that observed after four repeated one second maximal voluntary contractions.

The mechanism responsible for twitch potentiation is not certain. Although force generation is increased, the size of the compound muscle action potential (CMAP) is unaltered. Epstein therefore reasoned that potentiation is 
a process increasing the contractility of muscle because muscle activation is unaltered. ${ }^{20}$ Indeed, in three of our subjects we measured diaphragm CMAPs before and after five second sustained PDImax manoeuvres; CMAPs remained the same. The biochemical events leading to force potentiation have not been fully established. There appears to be a strong temporal relationship between twitch potentiation and phosphorylation of myosin light chains. ${ }^{21}$ Other workers have demonstrated that twitch potentiation is reduced by calcium antagonists. ${ }^{22}$

In our laboratory we rest subjects for 20 minutes after positioning balloon catheters before making twitch PDI measurements to avoid potentiated twitches. Other workers have suggested shorter rest times ${ }^{19}$ but we would argue that these investigators underestimated the time for recovery due to the variability of their data.

It should be noted that a single supramaximal twitch produces approximately $20 \%$ of PDImax; in a rested normal subject during tidal breathing the force generated by the diaphragm is often less than $5 \%$ of PDImax. Therefore it is likely that a single supramaximal twitch will have a potentiating action. Indeed, we have often observed that the first two or three twitches performed after a 20 minute rest are of reduced amplitude when compared with the subsequent series of twitches. For this reason when we measure twitch PDI, as the mean of a series of twitches, we perform single twitches at fixed time intervals, typically 30 seconds apart, discarding the first three twitches. We believe this eliminates variability in twitch PDI resulting from changing levels of "twitch on twitch" potentiation.

The degree of potentiation observed in this study following maximal activation was large; increases in twitch amplitude greater than $50 \%$ were observed. The twitch appeared in all runs to return to control values within 20 minutes. It is possible that twitch potentiation has been underestimated in previously published studies and critical review of such studies may be warranted. We conclude that potentiation must be considered in any protocol which involves measurement of twitch pressure, particularly when measurement is made in association with vigorous inspiratory manoeuvres.

1 Black LF, Hyatt RE. Maximal respiratory pressures: normal values and relationships to age and sex. Am Rev Respir Dis 1969;99:696-702.

2 Miller JM, Moxham J, Green M. The maximum sniff in the assessment of diaphragm function in man. Clin $\mathrm{Sci}$ 1985;69:91-6.

3 Mier A, Brophy C, Moxham J, Green M. Assessment of diaphragm weakness. Am Rev Respir Dis 1988;137:877-83.

4 Bellemare F, Bigland-Ritchie B. Assessment of human diaphragm strength and activation using phrenic nerve stimulation. Respir Physiol 1984;58:263-77.

5 Moxham J, Morris AJR, Spiro SG, Edwards RHT. Contractile properties and fatigue of the diaphragm in man. Thorax 1981;36:164-8.

6 Aubier M, Farkas G, De Troyer A, Mozes R, Roussos C. Detection of diaphragmatic fatigue in man by phrenic stimulation. F Appl Physiol 1981;50:538-44.

7 Mier A, Brophy C, Moxham J, Green M. Twitch pressures in the assessment of diaphragm weakness. Thorax 1989; 44:990-6.

8 Moxham J, Miller J, Wiles CM, Morris AJR, Green M. Effect of aminophylline on the human diaphragm. Thorax 1985;40:288-92.

9 Levy RD, Nava S, Gibbons L, Bellemare F. Aminophylline and human diaphragm strength in vivo. $\mathcal{F}$ Appl Physiol 1990;68:2591-6.

10 Hubmayr RD, Litchy WJ, Gay PC, Nelson SB. Transdiaphragmatic twitch pressure: effects of lung volume and diaphragmatic twitch pressure: effects of lung volume and
chest wall shape. Am Rev Respir Dis 1989;139:647-52.

11 Smith J, Bellemare F. Effect of lung volume on in vivo contraction characteristics of human diaphragm. $\mathcal{f} A p p l$ Physiol 1987;62:1893-900.

12 Similowski T, Fleury B, Launois S, Cathala HP, Bouche P, Derenne JP. Cervical magnetic stimulation: a new painless method for bilateral phrenic nerve stimulation in conscious humans. F Appl Physiol 1989;67:1311-8.

13 Vandervoort AA, Quinlan J, McComas AJ. Twitch potentiation after voluntary contraction. Exp Neurol 1983; 81:141-52.

14 Milic-Emili J, Mead J, Turner JM, Glauser EM. Improved technique for estimating pleural pressure from esophageal balloons. F Appl Physiol 1964;19:207-11.

5 Baydur A, Pangiotis K, Behrakis K, Zin WA, Jaeger M, Milic-Emili J. A simple method of assessing the validity of the esophageal balloon technique. Am Rev Respir Dis 1982;126:788-91.

16 Agostoni E, Rahn $\mathrm{H}$. Abdominal and thoracic pressures at different lung volumes. 7 Appl Physiol 1960;15:1087-92.

17 Barker AT, Freeston IL, Jalinous R, Jaratt JA. Magnetic stimulation of the human brain and peripheral nervous system: an introduction and the results of an initial clinical evaluation. Neurosurgery 1987;20:100-9.

18 Wragg S, Aquilina R, Moran J, Ridding M, Hamnegard $\mathrm{C}$, Fearn T, et al. A comparison of cervical magnetic stimulation and bilateral percutaneous electrical stimulation of the phrenic nerves in normal subjects. Eur Respir f 1994;7:1788-92.

19 Mador MJ, Magalang UJ, Kufel TJ. Twitch potentiation following voluntary diaphragmatic contraction. $A m f$ following voluntary diaphragmatic con

20 Epstein RA, Epstein RM. The electromyogram and the mechanical response of indirectly stimulated muscle in anaesthetised man following curarization. Anesthesiology 1973;38:212-23.

21 Moore RL, Houston ME, Iwamoto GA, Stull JT. Phosphorylation of rabbit skeletal muscle myosin in situ. $\mathcal{F}$ Cell Physiol 1985;125:301-5.

22 Williams JH. Depression of posttetanic twitch potentiation by low calcium and calcium channel antagonists. $f$ Appl Physiol 1990;69:1093-7. 